\title{
Identification of Hypoxanthine Transport and Xanthine Oxidase Activity in Brain Capillaries
}

\author{
A. Lorris Betz \\ Departments of Pediatrics and Neurology, University of Michigan, Ann Arbor, Michigan, U.S.A.
}

\begin{abstract}
Microvessel segments were isolated from rat brain and used for studies of hypoxanthine transport and metabolism. Compared to an homogenate of cerebral cortex, the isolated microvessels were 3.7-fold enriched in xanthine oxidase. Incubation of the isolated microvessels with labeled hypoxanthine resulted in its rapid uptake followed by the slower accumulation of hypoxanthine metabolites including xanthine and uric acid. The intracellular accumulation of these metabolites was inhibited by the xanthine oxidase inhibitor allopurinol. Hypoxanthine transport into isolated capillaries was inhibited by adenine but not by representative pyrimidines or nucleosides. Similar results were obtained when blood to brain transport of hypoxanthine in vivo was measured using the
\end{abstract}

intracarotid bolus injection technique. Thus, hypoxanthine is transported into brain capillaries by a transport system shared with adenine. Once inside the cell, hypoxanthine can be metabolized to xanthine and uric acid by xanthine oxidase. Since this reaction leads to the release of oxygen radicals, it is suggested that brain capillaries may be susceptible to free radical mediated damage. This would be most likely to occur in conditions where the brain hypoxanthine concentration is increased as following ischemia. Key Words: Blood-brain barrierBrain microvessels - Adenine transport-AllopurinolCerebral ischemia. Betz A. L. Identification of hypoxanthine transport and xanthine oxidase activity in brain capillaries. $J$. Neurochem. 44, 574-579 (1985).
Under normal circumstances, most purines in brain exist as nucleotides, principally the adenine nucleotides. However, in pathologic conditions such as ischemia (Kleihues et al., 1974; Berne et al., 1974; Winn et al., 1979) or hypotension (Winn et al., 1980 ), brain adenine nucleotides are degraded to the corresponding nucleosides (adenosine and inosine) and purine bases (adenine and hypoxanthine). When the circulation is restored, adenosine and, to a lesser extent, hypoxanthine (HX) and inosine are reincorporated into adenine nucleotides (Kleihues et al., 1974; Winn et al., 1980a). Alternatively, if the brain contains significant xanthine oxidase (EC 1.2.3.2) HX could be further degraded to xanthine and uric acid coupled with the release of superoxide radicals. There has been little study of this pathway in brain.

Xanthine oxidase is not uniformly distributed among all tissues. It is found in highest activity in liver and intestinal mucosa and is relatively low in whole brain (Al-Khalidi and Chaglassian, 1965). A recent immunocytochemical study demonstrated the presence of substantial xanthine oxidase in var-

Received April 20, 1984; accepted July 26, 1984.

Address correspondence and reprint requests to A. Lorris Betz, M.D., Ph.D., R6060 Kresge Research II, University of Michigan, Ann Arbor, MI 48109, U.S.A. ious vascular endothelial cells (Jarasch et al., 1981); however, brain blood vessels were not examined. In the intestine, xanthine oxidase appears to play an important role in the pathogenesis of ischemic injury (Parks and Granger, 1983). The evidence suggests that the superoxide radical produced by xanthine oxidase damages the vascular wall and increases protein permeability either directly or through subsequent formation of hydroxyl radicals. Free radicals have also been implicated in the pathogenesis of ischemic injury to brain (Demopoulos et al., 1980) and intracerebral injection of exogenous xanthine oxidase and $\mathrm{HX}$ causes brain edema and blood-brain barrier breakdown (Chan et al., 1984). Since the brain HX concentration increases during ischemia (Kleihues et al., 1974); Berne et al., 1974; Winn et al., 1979), the possibility exists for reaction with an endogenous xanthine oxidase resulting in the production of oxygen radicals and subsequent free radical-mediated injury to brain.

The present report establishes the presence of xanthine oxidase in isolated brain capillaries. In ad-

Abbreviations used: BUI, Brain uptake index; HX, hypoxanthine, PBS, phosphate-buffered saline. 
dition, brain capillaries are capable of taking up $\mathrm{HX}$ both in vivo and in vitro. Intracellular HX is subsequently degraded to xanthine and uric acid or incorporated into other compounds by an energy dependent process. The potential exists, therefore, for xanthine oxidase mediated damage to brain capillaries in ischemia.

\section{MATERIALS AND METHODS}

\section{Isolation of brain capillaries}

Microvessels were isolated from rat brain cortex by homogenization, dextran gradient centrifugation, and glass bead filtration as described previously (Betz, 1983). The purity of the preparation was monitored by phase microscopy. The final capillary pellet was suspended in Dulbecco's phosphate-buffered saline with $1 \mathrm{mM} \mathrm{CaCl}{ }_{2}$, $5 \mathrm{mM}$ glucose, and $1 \%$ bovine serum albumin (PBS). The capillary protein of albumin-free aliquots was measured using the Biorad dye binding assay.

\section{HX transport in vitro}

Aliquots of isolated microvessels containing approximately $0.2 \mathrm{mg}$ of protein were preincubated for $30 \mathrm{~min}$ at $37^{\circ} \mathrm{C}$ in PBS or in glucose-free PBS containing $1 \mathrm{mM} 2,4-$ dinitrophenol and $5 \mathrm{~m} M$ sodium iodoacetate (energy-depleting buffer). HX uptake was initiated by the addition of $\left[{ }^{14} \mathrm{C}\right]$ or $\left[{ }^{3} \mathrm{H}\right] \mathrm{HX}$ (final concentrations 4 or $18 \mu \mathrm{Ci} / \mathrm{ml}$, respectively) and terminated at various times by rapid filtration and washing on cellulose triacetate filters using ice-cold PBS (Betz et al., 1979; Betz, 1983).

Release of intracellular HX was studied in microvessels that had been preincubated in PBS or energy-depleting buffer for $30 \mathrm{~min}$, then incubated an additional $20 \mathrm{~min}$ in the same buffer now containing $\left[{ }^{14} \mathrm{C}\right] \mathrm{HX}$. Efflux was initiated by a 20 -fold dilution of the capillary suspension with isotope-free buffer. Aliquots were removed after various periods of time, filtered, and washed.

Radiolabeled metabolites of $\left[{ }^{14} \mathrm{C}\right] \mathrm{HX}$ were isolated in one experiment. Energy-depleted microvessels were incubated for 20 min with $\left[{ }^{14} \mathrm{C}\right] \mathrm{HX}$ and then collected and washed by filtration on glass fiber filters $(\mathrm{GF} / \mathrm{C})$. The capillary containing filters were immediately placed in water and boiled for $5 \mathrm{~min}$. After removal of the filter and centrifugation to remove precipitated proteins, the supernate was lyophylized. The residue was dissolved in water containing $1 \mathrm{mM}$ each of carrier $\mathrm{HX}$ and xanthine and subjected to electrophoresis on cellulose acetate strips as described by Kizaki and Sakurada (1977). The strips were cut into 10 pieces and placed in scintillation vials for determination of the ${ }^{14} \mathrm{C}$ content. The location of $\mathrm{HX}$ and xanthine was determined by exposure of the intact strips to ultraviolet light.

\section{HX transport in vivo}

Brain uptake of HX, xanthine, and allopurinol was measured in $250-300 \mathrm{~g}$ Sprague-Dawley rats using the intracarotid injection technique of Oldendorf (1971). ${ }^{3} \mathrm{H}_{2} \mathrm{O}$ was used as the reference compound for ${ }^{14} \mathrm{C}$-labeled $\mathrm{HX}$, xanthine, and allopurinol whereas $\left[{ }^{14} \mathrm{C}\right]$ butanol was the reference for $\left[{ }^{3} \mathrm{H}\right] \mathrm{HX}$ injections. All results were expressed as the brain uptake index (BUI) relative to butanol using a conversion factor for the relative uptake of ${ }^{3} \mathrm{H}_{2} \mathrm{O}$ versus $\left[{ }^{14} \mathrm{C}\right]$ butanol $(0.734 \pm 0.071 \mathrm{SD}, \mathrm{n}=4)$ determined in separate experiments.

\section{Enzyme assays}

Alkaline phosphatase was measured according to the method of Linhardt and Walter (1965). Homogenates of microvessels were prepared by sonication of a fresh microvessel suspension followed by freezing, thawing, and resonication. Homogenates of cortex were obtained during the capillary preparation, diluted and then treated the same as the microvessel sample. Xanthine oxidase was determined by the conversion of $\left[{ }^{14} \mathrm{C}\right] \mathrm{HX}$ to $\left[{ }^{[4} \mathrm{C}\right]$ xanthine and uric acid using a 30-min assay as described elsewhere (Kizaki and Sakurada, 1977).

\section{Statistical analysis}

Student's $t$ test for nonpaired data was used to test for significant differences between means. The Bonferroni correction was used when multiple simultaneous comparisons were made (Wallenstein et al., 1980).

\section{Materials}

$\left[8-{ }^{14} \mathrm{C}\right] \mathrm{HX}(53 \mathrm{mCi} / \mathrm{mmol})$ and $\left[\mathrm{G}-{ }^{3} \mathrm{H}\right] \mathrm{HX}(5.7 \mathrm{Ci} / \mathrm{mmol})$ were obtained from Amersham (Arlington Heights, IL). Radiochemical purity was found to be $>98.5 \%$ using paper chromatography in $t$-butanol-ethyl methyl ketonewater-ammonia $(4: 3: 2: 1) .\left[2-{ }^{14} \mathrm{C}\right]$ Xanthine $(48 \mathrm{mCi} / \mathrm{mmol})$ and $\left[2-{ }^{14} \mathrm{C}\right.$ ]allopurinol $(48 \mathrm{mCi} / \mathrm{mmol})$ were purchased from Research Products International (Mount Prospect, IL) and their radiochemical purity was verified using paper chromatography in $2 \mathrm{M} \mathrm{HCl}$ or isopropanol-ammonia-water $(80: 5: 15)$. $\left[1-{ }^{14} \mathrm{C}\right] \mathrm{Butanol}(1 \mathrm{mCi} / \mathrm{mmol})$ and ${ }^{3} \mathrm{H}_{2} \mathrm{O}(1 \mathrm{Ci} / \mathrm{g})$ were obtained from New England Nuclear (Boston, MA). Dulbecco's PBS was purchased from Grand Island Biological (Grand Island, NY). The dyebinding reagent and $\gamma$-globulin standard used in protein determinations were purchased from Biorad (Richmond, CA). Metricel filters and Sepraphore III electrophoresis strips were manufactured by Gelman Sciences (Ann Arbor, MI).

\section{RESULTS}

Compared to a brain homogenate, brain microvessels are known to be enriched in a number of enzymes including alkaline phosphatase and $\gamma$-glutamyl transpeptidase (Goldstein et al., 1975). The microvessels used in the present study typically showed a 10-fold enrichment in alkaline phosphatase activity (Table 1). Xanthine oxidase was also measurable in capillaries at an activity that was three- to fourfold higher than its activity in an homogenate of cortex. This result suggests that brain capillaries are enriched in xanthine oxidase but they do not contain all of the xanthine oxidase present in brain. It should be noted that the normal form of this enzyme in vivo is probably as xanthine dehydrogenase and it is converted to the oxidase form when the tissue is homogenized (Battelli et al., 1972).

When isolated brain microvessels were incubated with $\left[{ }^{14} \mathrm{C}\right] \mathrm{HX}$ (Fig. 1), there was rapid (within $1 \mathrm{~min}$ ) uptake into a space approximating the intracellular water space $(2.2 \mu \mathrm{l} / \mathrm{mg})$ as determined by sugar equilibration (Betz et al., 1979). With longer incubation, untreated microvessels exhibited accumu- 
TABLE 1. Comparison of enzyme activities in brain microvessels and brain homogenate

\begin{tabular}{llcr}
\hline \multicolumn{1}{c}{ Enzyme } & Microvessels & Homogenate & Ratio \\
\hline Alkaline & & & \\
$\quad$ phosphatase & $4556 \pm 98$ & $441 \pm 6$ & 10.3 \\
Xanthine oxidase & $8.49 \pm 2.30$ & $2.26 \pm 0.97$ & 3.7 \\
\hline
\end{tabular}

Activities are expressed as nmol of product produced $/ \mathrm{mg} / \mathrm{h}$ at $37^{\circ} \mathrm{C}$. Results are the means $\pm \mathrm{SD}$ of four determinations.

lation of intracellular ${ }^{14} \mathrm{C}$ to a level that, at $20 \mathrm{~min}$, was sevenfold greater than the initial distribution space. This suggests either uptake of $\left[{ }^{14} \mathrm{C}\right] \mathrm{HX}$ against a concentration gradient or the formation of metabolites of $\left[{ }^{14} \mathrm{C}\right] \mathrm{HX}$. The accumulation of intracellular radioactivity was partially energy-dependent since prior energy depletion of the capillaries reduced, but did not eliminate, the amount of ${ }^{14} \mathrm{C}$ accumulated within the cells. Addition of the specific xanthine oxidase inhibitor, allopurinol, to the energy-depleted microvessels caused an additional reduction of ${ }^{14} \mathrm{C}$ accumulation to a level that was the same as the initial distribution space. This indicates that a portion of the radioactivity within energy-depleted microvessels is in the form of xanthine or uric acid.

Further evidence for intracellular metabolism of $\left[{ }^{14} \mathrm{C}\right] \mathrm{HX}$ was found in a study of the release of radioactivity from preloaded microvessels. Since HX appears to be rapidly taken up by the cells, free HX might also be rapidly released from the cells when extracellular radioactivity is removed. Metabolites of HX may not be released as rapidly. As shown in Fig. 2, energy-depleted microvessels incubated with allopurinol released nearly all of their intracellular radioactivity within $2 \mathrm{~min}$. This suggests that cells in this group contain mostly free HX. In contrast, untreated or energy-depleted microvessels released only a portion of their radioactivity. Nevertheless, the total amount lost in $5 \mathrm{~min}$ was the

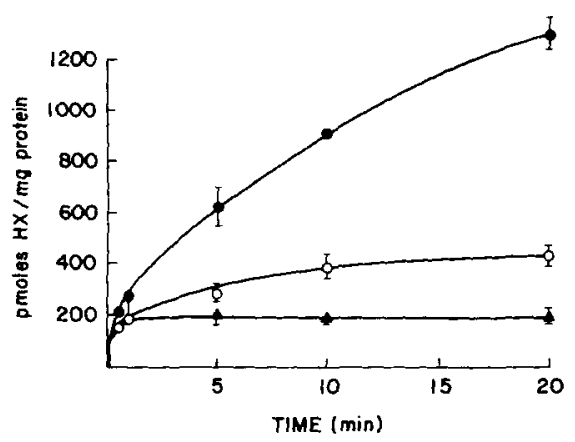

FIG. 1. Time course for uptake of $0.08 \mathrm{mM}\left[{ }^{14} \mathrm{C}\right] \mathrm{HX}$ at $37^{\circ} \mathrm{C}$. Microvessels were preincubated for $30 \mathrm{~min}$ in control buffer (4), energy-depleting buffer (O), or energy-depleting buffer containing $0.1 \mathrm{mM}$ allopurinol (\$). Results shown are averages of three determinations $\pm \mathrm{SD}$

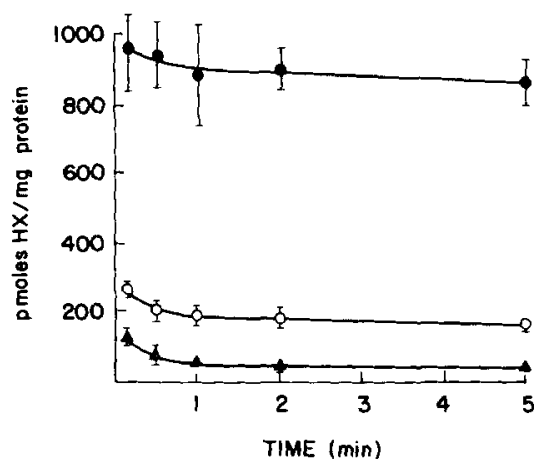

FIG. 2. Efflux of $\left[{ }^{14} \mathrm{C}\right] \mathrm{HX}$ from preloaded capillaries. Isolated microvessels were incubated for $30 \mathrm{~min}$ at $37^{\circ} \mathrm{C}$ in control buffer (๑), energy-depleting buffer $(O)$, or energy depleting buffer containing $0.1 \mathrm{mM}$ allopurinol $(\Delta)$. All solutions were then made $0.08 \mathrm{mM}$ in $\left[{ }^{14} \mathrm{C}\right] \mathrm{HX}$ and incubated an additional $20 \mathrm{~min}$. Efflux was initiated by dilution of extracellular radioactivity. Results shown are averages of three determinations \pm SD.

same as that lost from the energy-depleted microvessels treated with allopurinol. It seems likely, therefore, that the cells contain a similar amount of free HX under all conditions and additional radioactivity is present as HX metabolites that do not readily cross the cell membrane.

Confirmation of intracellular production of xanthine or uric acid in energy-depleted microvessels was obtained by electrophoretic separation of intracellular contents after incubation with $\left[{ }^{14} \mathrm{C}\right] \mathrm{HX}$ (Fig. 3). Radioactivity was found distributed between two peaks which corresponded to the migration of HX and xanthine + uric acid. The electrophoresis system used did not permit separation of the latter two products of xanthine oxidase. The amount of radioactivity in the xanthine + uric acid peak was greatly reduced by incubation of the capillaries with allopurinol. Thus, isolated brain micro-

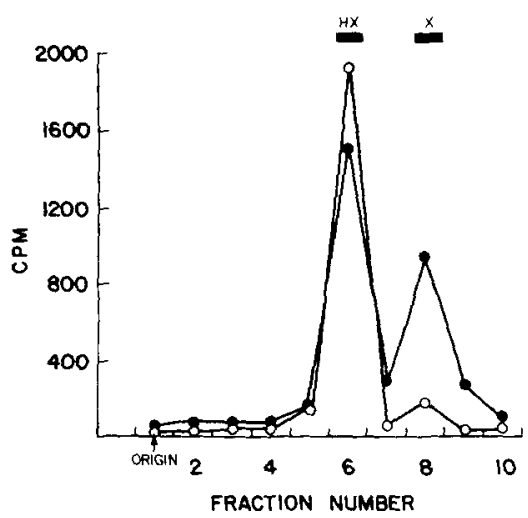

FIG. 3. Separation of intracellular $H X$ and metabolites. Energy-depleted microvessels were incubated for $20 \mathrm{~min}$ with $80 \mathrm{mM}\left[{ }^{14} \mathrm{C}\right] \mathrm{HX}$ either without (0) or with (O) $\mathrm{mM}$ allopurinol. intracellular radioactivity was extracted and subjected to paper electrophoresis. The migration of carrier hypoxanthine $(H X)$ and xanthine $(X)$ was observed using ultraviolet light. 
vessels are enriched in xanthine oxidase and are capable of taking up extracellular HX and converting it to xanthine.

To characterize HX transport further, it is important to be able to study the uptake process independent of subsequent metabolism. As noted previously, HX uptake by capillaries is very rapid and the intracellular and extracellular radioactivity approached equilibration by $1 \mathrm{~min}$. However, conversion to xanthine was insignificant at incubation times of $<1 \mathrm{~min}$ (Fig. 1). Thus, shorter incubation times permit an estimate of the rate of uptake. In addition, reduction of the incubation temperature will slow transport slightly and facilitate the measurement of a transport rate (Betz et al., 1979). Finally, a low substrate concentration is required in order to appreciate the competitive effects of potential transport inhibitors. Therefore $\left[{ }^{3} \mathrm{H}\right] \mathrm{HX}$ was used in this part of the study since it can be obtained in higher specific activity than $\left[{ }^{14} \mathrm{C}\right] \mathrm{HX}$. The time course for uptake of $\left[{ }^{3} \mathrm{H}\right] \mathrm{HX}$ at $22^{\circ} \mathrm{C}$ is shown in Fig. 4. A $30 \mathrm{~s}$ time point was chosen for subsequent study of transport inhibitors. Although use of this time point clearly does not represent a true initial rate of uptake it does allow testing the effect of potential transport modifiers (Betz et al., 1979). The results of studies on HX uptake in the presence of a variety of compounds are shown in Table 2. Only adenine or $\mathrm{HX}$ itself significantly reduced $\left[{ }^{3} \mathrm{H}\right] \mathrm{HX}$ uptake. The pyrimidines thymine and cytosine had a mild stimulatory effect on uptake. This phenomenon has also been observed in studies of HX uptake by cultured Novikoff hepatoma cells (Marz et al., 1979) and the mechanism is not known. Several purine nucleosides, xanthine, uric acid, and the potent adenosine transport inhibitor dipyridamole (Wu and Phillis, 1982) had no effect.

Uptake of HX by isolated capillaries may occur across the antiluminal and/or the luminal membranes of the endothelial cell. To examine HX transport across the luminal membrane directly, the intracarotid bolus injection technique of Oldendorf

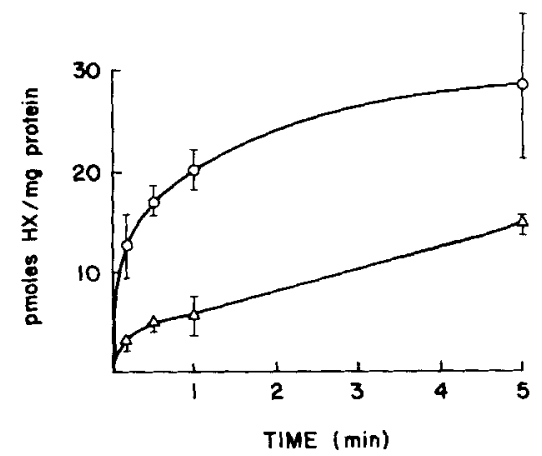

FIG. 4. Time course for uptake of $0.02 \mathrm{mM}\left[{ }^{3} \mathrm{H}\right] \mathrm{HX}$ at $22^{\circ} \mathrm{C}$ $(O)$ and $4^{\circ} \mathrm{C}(\triangle)$. Isolated microvessels were preincubated for $30 \mathrm{~min}$ in energy-depleted buffer. Results shown are the averages of three determinations \pm SD.
TABLE 2. Effects of various agents on hypoxanthine uptake by microvessels

\begin{tabular}{cc}
\hline Agent & Control uptake $(\%)$ \\
\hline Purines & $55 \pm 7^{a}$ \\
Hypoxanthine & $61 \pm 5^{a}$ \\
Adenine & $128 \pm 20^{b}$ \\
Pyrimidines & $118 \pm 11^{b}$ \\
Cytosine & $104 \pm 11$ \\
Thymine & $112 \pm 22$ \\
Uracil & $113 \pm 18$ \\
Nucleosides & $107 \pm 37$ \\
lnosine & $100 \pm 9$ \\
Adenosine & $117 \pm 16$ \\
Uridine & $119 \pm 20$ \\
Other agents & $87 \pm 12$ \\
Xanthine & Uric acid \\
Dipyridamole & Allopurinol \\
\hline
\end{tabular}

Uptake of $10 \mu M\left[{ }^{3} \mathrm{H}\right] \mathrm{HX}$ was measured during a 30 -s incubation at $22^{\circ} \mathrm{C}$. Results were obtained from two separate capillary preparations and combined. The control uptake was $4.9 \pm$ $0.5 \mathrm{pmol} / \mathrm{mg}$ protein $/ 30 \mathrm{~s}(\mathrm{n}=12)$. Inhibitors were added to a final concentration of $0.5 \mathrm{~m} M$ except for dipyridamole which was present at $0.05 \mathrm{mM}$. The results are shown as the percent of control uptake for the mean \pm SD of six determinations.

${ }^{a} \mathrm{p}<0.001$ compared to control; ${ }^{b} \mathrm{p}<0.03$ compared to control.

(1971) was used. As shown in Table 3, brain uptake of HX was small but significantly greater than xanthine, whose uptake was similar to that seen for substances that do not cross the blood-brain barrier (Oldendorf, 1971). Increasing the HX concentration to $1 \mathrm{mM}$ resulted in a $20 \%$ reduction in HX uptake, suggesting the presence of a saturable transport

TABLE 3. Brain uptake of $H X$, xanthine, and allopurinol in vivo

\begin{tabular}{lccrc} 
Compound & $\begin{array}{c}\text { Concentration } \\
(\mathrm{m} M)\end{array}$ & $\begin{array}{c}\text { Additions } \\
(\mathrm{m} M)\end{array}$ & $\mathrm{n}$ & BUI \\
\hline HX & 0.005 & - & 3 & $6.21 \pm 1.29$ \\
HX & 0.090 & - & 10 & $5.42 \pm 1.14$ \\
HX & 1.000 & - & 7 & $4.96 \pm 0.36^{\prime \prime}$ \\
HX & 0.090 & Adenine $(0.10)$ & 5 & $4.05 \pm 1.30$ \\
HX & 0.090 & Adenine $(0.50)$ & 10 & $3.84 \pm 0.83^{\circ}$ \\
HX & 0.090 & Adenosine $(0.50)$ & 8 & $5.85 \pm 0.42$ \\
HX & 0.090 & Thymine $(0.50)$ & 3 & $5.41 \pm 0.50$ \\
Xanthine & 0.025 & - & 4 & $1.80 \pm 0.37$ \\
Xanthine & 0.50 & - & 4 & $2.29 \pm 0.82$ \\
Allopurinol & 0.096 & - & 5 & $10.4 \pm 1.23$ \\
Allopurinol & 1.000 & Adenine $(0.50)$ & 5 & $7.79 \pm 1.69^{\prime}$ \\
Allopurinol & 0.096 & - & 5 & $7.72 \pm 1.02^{\prime}$ \\
\hline
\end{tabular}

Brain uptake of each compound was determined $5 \mathrm{~s}$ after the intracarotid bolus injection of $0.2 \mathrm{cc}$ of PBS containing various concentrations of either ${ }^{3} \mathrm{H}$ - or ${ }^{14} \mathrm{C}$-labeled substrates. Unlabeled compounds were also added in some cases. The BUI is expressed as the percent of butanol uptake and the results are means $\pm \mathrm{SD}$.

${ }^{a} \mathrm{p}<0.05$ compared to $0.005 \mathrm{mM} \mathrm{HX} ;{ }^{b} \mathrm{p}<0.01$ compared to $0.09 \mathrm{~m} M$ HX alone; $\mathrm{p}<0.01$ compared to $0.096 \mathrm{~m} M$ allopurinol. 
system. This idea is supported by the significant reduction in HX uptake caused by adenine. Allopurinol also appears to enter brain from blood by a saturable process that can be inhibited by adenine. Taken together, these results indicate that HX and allopurinol are transported across the luminal membrane of the brain capillary by virtue of a relatively low affinity for the blood-brain barrier adenine transport system (Cornford and Oldendorf, 1975).

\section{DISCUSSION}

This study demonstrates that brain capillaries, like capillary endothelial cells of other tissues (Jarasch et al., 1981), contain the enzyme xanthine oxidase. Extracellular HX can be transported into brain capillaries and metabolized by xanthine oxidase to xanthine. Brain uptake of HX in vivo indicates that blood-borne HX can enter the capillary across the luminal membrane. However, because of the rapidity with which HX is taken up by isolated microvessels, it seems likely that HX enters the capillary across the antiluminal membrane as well.

Experiments performed in the presence of various structurally related compounds suggest that, both in vivo and in vitro, $\mathrm{HX}$ uptake occurs by a transport system shared with adenine. This is in contrast with certain cultured cells where HX uptake is more strongly inhibited by nucleosides and only slightly inhibited by adenine (Marz et al., 1979; Slaughter and Barnes, 1979). The HX transporter in brain microvessels may be more closely related to the one found in human erythrocytes that has an apparent $K_{\mathrm{m}}$ for HX of $0.4 \mathrm{mM}$ and that is inhibited by adenine (Lassen, 1967).

Cornford and Oldendorf also examined brain uptake of hypoxanthine following intracarotid injection (Cornford and Oldendorf, 1975). They obtained a BUI for HX similar to that of compounds that do not enter brain. However, unlabeled $\mathrm{HX}$ was capable of inhibiting adenine uptake with a $K_{\mathrm{i}}$ of 0.097 $\mathrm{m} M$. HX had no effect on a separate nucleoside transport system. My results indicate a somewhat greater uptake of HX itself and confirm its interaction with the adenine carrier.

When the isolated capillaries were not energydepleted, there was substantial incorporation of HX into other metabolites. Although not characterized in the present study, these metabolites are likely to be adenine nucleotides formed by conversion of HX to IMP by hypoxanthine phosphoribosyltransferase (EC 2.4.2.8). This enzyme plays a role in the "salvage pathway" that helps conserve the adenine nucleotide pool and that is known to be very active in brain capillaries (Wu and Phillis, 1982). Therefore, once inside the endothelial cell, HX may be either irreversibly degraded to xanthine and uric acid or reincorporated into the adenine nucleotide pool.
The demonstration of xanthine oxidase in brain microvessels indicates the presence of an important oxygen radical producing enzyme in this tissue. Although, the activity of free-radical detoxifying enzymes such as superoxide dismutase, catalase and glutathione peroxidase has not yet been determined, the association of oxygen radical-producing enzymes with brain capillaries may predispose these microvessels to damage by endogenously produced free radicals. Indeed, other investigators have demonstrated that the permeability of systemic vascular beds is increased by free radicals generated from exogenous xanthine oxidase (Ohmori et al., 1978; Del Maestro et al., 1981). Furthermore, the injection of exogenous xanthine oxidase plus HX into brain causes injury to brain capillaries and breakdown of the blood-brain barrier (Chan et al., 1984). There is also good evidence that free radicals produced by endogenous xanthine oxidase cause damage to intestinal capillaries in ischemia (Parks and Granger, 1983). Therefore, the presence of xanthine oxidase in brain capillaries coupled with the increase in brain HX during ischemia suggest a potential role of oxygen-derived free radicals as a cause of pathologic alterations in brain capillary function during ischemia.

Acknowledgments: I thank Otho Artis, Jr. for his excellent technical assistance and Dr. Gary Goldstein for many helpful suggestions. This work was supported by a grant-in-aid and an Established Investigatorship from the American Heart Association through funds contributed in part by the Michigan affiliate.

\section{REFERENCES}

AI-Khalidi U. A. S. and Chaglassian T. H. (1965) The species distribution of xanthine oxidase. Biochem. J. 97, 318-320.

Battelli M. G., Della Corte E., and Stirpe F. (1972) Xanthine oxidase type $D$ (dehydrogenase) in the intestine and other organs of the rat. Biochem. $J .126,747-749$.

Berne R. M., Rubio R., and Curnish R. R. (1974) Release of adenosine from ischemic brain. Effect on cerebral vascular resistance and incorporation into cerebral adenine nucleotides. Circ. Res. 35, 262-271.

Betz A. L. (1983) Sodium transport in capillaries isolated from rat brain. $J$. Neurochem. 41, 1150-1157.

Betz A. L., Csejtey J., and Goldstein G. W. (1979) Hexose transport and phosphorylation by capillaries isolated from rat brain. Am. J. Physiol. 236, C96-C102.

Chan P. H., Schmidley J. W., Fishman R. A., and Longar S. M. (1984) Brain injury, edema, and vascular permeability changes induced by oxygen-derived free radicals. Neurology 34, 315-320.

Cornford E. M. and Oldendorf W. H. (1975) Independent bloodbrain barrier transport systems for nucleic acid precursors. Biochim. Biophys. Acta 394, 211-219.

Del Maestro R. F., Bjork J., and Arfors K.-E. (1981) Increase in microvascular permeability induced by enzymatically generated free radicals. Microvasc. Res, 22, 239-254.

Demopoulos H. B., Flamm E. S., Pietronigro D. D., and Seligman M. L. (1980) The free radical pathology and the microcirculation in the major central nervous system disorders. Acta Physiol. Scand. (Suppl.) 492, 91-119.

Goldstein G. W., Wolinsky J. S., Csejtey J., and Diamond I. 
(1975) Isolation of metabolically active capillaries from rat brain. J. Neurochem. 25, 715-717.

Jarasch E.-D., Grund C., Bruder G., Heid H. W., Koenan T. W., and Franke W. W. (1981) Localization of xanthine oxidase in mammary-gland epithelium and capillary endothelium. Cell 25, 67-82.

Kizaki H. and Sakurada T. (1977) Simple micro-assay methods for enzymes of purine metabolism. J. Lab. Clin. Med. 89, $1135-1144$.

Kleihues P., Kobayashi K., and Hossman K.-A. (1974) Purine nucleotide metabolism in the cat brain after one hour of complete ischemia. J. Neurochem. 23, 417-425.

Lassen U. V. (1967) Hypoxanthine transport in human erythrocytes. Biochim. Biophys. Acta 135, 146-154.

Linhardt K. and Walter K. (1965) Determination in serum with p-nitrophenylphosphate, in Methods of Enzymatic Analysis (Bergmeyer U., ed), pp 783-785. Academic Press, New York.

Marz R., Wohlhueter R. M., and Plagemann P. G. W. (1979) Purine and pyrimidine transport and phosphoribosylation and their interaction in overall uptake by cultured mammalian cells. J. Biol. Chem. 254, 2329-2338.

Ohmori H., Komoriya K., Azuma A., Hashimoto Y., and Kurozumi S. (1978) Xanthine oxidase-induced foot-edema in rats: involvement of oxygen radicals. Biochem. Pharancol. $27,1397-1400$.
Oldendorf W. H. (1971) Brain uptake of radiolabeled amino acids, amines, and hexoses after arterial injection. Am. J. Physiol. 221, 1629-1638.

Parks D. A. and Granger D. N. (1983) Ischemia-induced vascular changes: role of xanthine oxidase and hydroxyl radicals. Am. J. Physiol. 245, G285-G289.

Slaughter R. S. and Barnes E. M., Jr. (1979) Hypoxanthine transport by chinese hamster lung fibroblasts: kinetics and inhibition by nucleosides. Arch. Biochem. Biophys. 197, $349-355$.

Wallenstein S., Zuckler C. I., and Fleiss J. L. (1980) Some statistical methods useful in circulation research. Circ. Res. 47, $1-9$.

Winn R. H., Rubio R., and Berne R. M. (1979) Brain adenosine production in the rat during 60 seconds of ischemia. Circ. Res. 45, 486-492.

Winn R. H., Park T. S., Curnish R. R., Rubio R., and Berne R. M. (1980a) Incorporation of adenosine and its metabolites into brain nucleotides. Am. J. Physiol. 239, H212H219.

Winn R. H., Welsh J. E., Rubio R., and Berne R. M. (1980b) Brain adenosine production in rat during sustained alteration in systemic blood pressure. Am.J. Physiol. 239, H636H641.

Wu P. H. and Phillis J. W. (1982) Uptake of adenosine by isolated rat brain capillaries. J. Neurochem. 38, 687-690. 